Yuriy Kharin

\title{
Robustness in Statistical Forecasting
}

4 ty Springer 


\author{
Yuriy Kharin \\ Department of Mathematical Modeling \\ and Data Analysis \\ Belarusian State University \\ Minsk \\ Belarus
}

ISBN 978-3-319-00839-4

ISBN 978-3-319-00840-0 (eBook)

DOI 10.1007/978-3-319-00840-0

Springer Cham Heidelberg New York Dordrecht London

Library of Congress Control Number: 2013948622

Mathematics Subject Classification (2010): 62-02,62M20,62M10,62G35,62-07, 62F35, 62C20,62P20

(C) Springer International Publishing Switzerland 2013

This work is subject to copyright. All rights are reserved by the Publisher, whether the whole or part of the material is concerned, specifically the rights of translation, reprinting, reuse of illustrations, recitation, broadcasting, reproduction on microfilms or in any other physical way, and transmission or information storage and retrieval, electronic adaptation, computer software, or by similar or dissimilar methodology now known or hereafter developed. Exempted from this legal reservation are brief excerpts in connection with reviews or scholarly analysis or material supplied specifically for the purpose of being entered and executed on a computer system, for exclusive use by the purchaser of the work. Duplication of this publication or parts thereof is permitted only under the provisions of the Copyright Law of the Publisher's location, in its current version, and permission for use must always be obtained from Springer. Permissions for use may be obtained through RightsLink at the Copyright Clearance Center. Violations are liable to prosecution under the respective Copyright Law.

The use of general descriptive names, registered names, trademarks, service marks, etc. in this publication does not imply, even in the absence of a specific statement, that such names are exempt from the relevant protective laws and regulations and therefore free for general use.

While the advice and information in this book are believed to be true and accurate at the date of publication, neither the authors nor the editors nor the publisher can accept any legal responsibility for any errors or omissions that may be made. The publisher makes no warranty, express or implied, with respect to the material contained herein.

Printed on acid-free paper

Springer is part of Springer Science+Business Media (www.springer.com) 


\section{Preface}

Statistical forecasting procedures are used to solve many applied problems in engineering, economics, finance, medicine, environmental studies, etc. For the majority of the developed statistical forecasting procedures, optimality (or asymptotic optimality as observation time increases) is proved w.r.t. the mean square forecast risk under the assumptions of an underlying hypothetical model. In practice, however, the observed data usually deviates from hypothetical models: random observation errors may be non-Gaussian, correlated, or inhomogeneous; the data may be contaminated by outliers, level shifts, or missing values; trend, regression, and autoregression functions do not necessarily belong to the declared parametric families, etc. Unfortunately, the forecasting procedures which have been proved to be optimal under the hypothetical model often become unstable under even small model distortions, resulting in forecast risks or mean square errors which are significantly higher than the theoretical values obtained in the absence of distortion. This necessitates the development of robust statistical algorithms, which are designed to retain most of their properties under small deviations from model assumptions.

The available textbooks on the subjects of statistical forecasting and robust statistical methods can be split into two distinct clusters. The first cluster includes books on theoretical and applied aspects of statistical forecasting where little or no attention is paid to robustness. The focus of these books is on various hypothetical models, methods, and computer algorithms used in forecasting, as well as their performance in the absence of model distortions.

The second cluster includes books on robust statistics which are dedicated to such diverse subjects as robust statistical parameter estimation, robust hypothesis testing in parametric (e.g., shift-scale) families of probability distributions, regression analysis, discriminant analysis, cluster analysis, time series analysis, etc. However, the topic of robustness in statistical forecasting remains barely touched upon, and little or no information is provided on such important aspects of forecasting as analysis of risk increments due to different types and levels of distortion, estimation of critical distortion levels for the traditional forecasting procedures, 